\title{
Article \\ Mechanical and Physical Properties of Differently Alloyed Sintered Steels as a Function of the Sintering Temperature
}

\author{
Milad Hojati *, Herbert Danninger (D) and Christian Gierl-Mayer (D) \\ Institute of Chemical Technologies and Analytics, Technische Universität Wien (TU Wien), \\ A-1060 Vienna, Austria; herbert.danninger@tuwien.ac.at (H.D.); christian.gierl@tuwien.ac.at (C.G.-M.) \\ * Correspondence: Milad.hojati@tuwien.ac.at
}

Citation: Hojati, M.; Danninger, H.; Gierl-Mayer, C. Mechanical and Physical Properties of Differently Alloyed Sintered Steels as a Function of the Sintering Temperature. Metals 2022, 12, 13. https://doi.org/ $10.3390 / \operatorname{met} 12010013$

Academic Editor: Jose Manuel Torralba

Received: 19 November 2021

Accepted: 16 December 2021

Published: 22 December 2021

Publisher's Note: MDPI stays neutral with regard to jurisdictional claims in published maps and institutional affiliations.

Copyright: (c) 2021 by the authors. Licensee MDPI, Basel, Switzerland. This article is an open access article distributed under the terms and conditions of the Creative Commons Attribution (CC BY) license (https:// creativecommons.org/licenses/by/ $4.0 /)$.

\begin{abstract}
In this paper, the effect of processes occurring during the sintering of four powder metallurgy steel grades on the resulting properties were investigated. This included three grades prepared from plain iron powder with admixed graphite, one grade alloyed also with elemental copper and another with Fe-Mn-Si masteralloy. One further grade was prepared from Cr-Mo pre-alloyed powder with admixed graphite. The effect of the sintering processes was examined in the temperature range of $700-1300{ }^{\circ} \mathrm{C}$ in an inert atmosphere (Ar). In order to study oxygen removal, DTA/TG runs linked with mass spectrometry (MS) as well as C/O elemental analysis were performed. Charpy impact tests and fractography studies were performed to study the effect of the temperature on the formation and growth of sintering contacts. Characterization also included metallography, dimensional change, sintered density, and hardness measurements to describe the dissolution of carbon and alloying elements during the process. Physical properties that were measured were electrical conductivity and coercive force. The results showed that, in all steels, the reduction of oxides that occur during the heating stage plays a key role in the formation and growth of the sintering contacts as well as in the completion of alloying processes. In the chromium alloy steel, the presence of the stable chromium oxides delays these processes up to higher temperatures, while in the other steels that are based on plain iron powder, these processes take place earlier in the heating stage, at lower temperatures. Compared to the standard $\mathrm{Fe}-\mathrm{C}$ and $\mathrm{Fe}-\mathrm{Cu}-\mathrm{C}$ grades, the $\mathrm{Cr}-\mathrm{Mo}$ steel requires more sophisticated sintering to ensure oxygen removal, but on the other hand it offers the best properties. The masteralloy variant, finally, can be regarded as a highly attractive compromise between manufacturing requirements, alloy element content, and product properties.
\end{abstract}

Keywords: powder metallurgy; iron-manganese masteralloy; sintering; Astaloy CrM; mechanical properties; physical properties

\section{Introduction}

The powder metallurgy (PM) press-and-sinter route is a well-known manufacturing process for the large-scale production of precision parts in a cost-effective manner. The constant demands for improved mechanical properties of the produced structural parts are met by the PM industry through various routes. One of the main advantages of the powder metallurgy process compared with ingot metallurgy is the larger flexibility in the material usage and the choice of the alloying route. This potential can usually be exploited easily when using conventional alloying elements of powder metallurgy such as carbon, copper, nickel, and/or molybdenum, e.g., by adding the elemental powders to the mix or by diffusion bonding them to the base powder. However, this method cannot be effective or practical when adding powders with higher sensitivity to oxygen. Some of these elements, such as chromium, silicon, and manganese, which are usually cheaper than $\mathrm{Ni}, \mathrm{Cu}$, and $\mathrm{Mo}$, are widely used in ingot metallurgy but have found less application in the powder metallurgy. The main challenge, regarding the use of oxygen-sensitive elements, is the formation of stable oxides especially on the particle surfaces, which can negatively affect the sintering process and the final properties of the sintered PM steels [1]. Therefore, 
minimizing oxidation during the sintering of PM steels that contain such elements seems to be an important task in order to have a successful sintering process. Furthermore, all powders that have been exposed to air at any time carry "natural" surface oxides, which are easily reducible in the case of $\mathrm{Cu}, \mathrm{Ni}$, and $\mathrm{Mo}$ but are more difficult to reduce for $\mathrm{Cr}, \mathrm{Mn}$, and $\mathrm{Si}$. One solution for both these problems could be to decrease the chemical activity of these elements by alloying them with elements of lower oxygen affinity [2]. To achieve this, there are basically two main routes: 1-using conventional pre-alloyed iron powder, e.g., commercial "Astaloy" grade powders, 2-by mixing a plain iron base powder with a masteralloy (MA) powder that contains the desired alloy elements in a combined form [3].

In addition to the selection of the alloying system, sintering conditions such as temperature, time, and atmosphere also play a key role on the final properties and microstructure of P/M steels, which have been the target of numerous investigations [4-6]. Basically, the most important sintering processes that can affect the final properties are the following [7]:

- Change of particle surface chemistry, in particular, the reduction of oxide layers covering the powder particles.

- $\quad$ Formation and growth of solid metallic bridges out of pressing contacts.

- Dissolution of alloy elements, in particular, carbon and distribution within the metallic matrix.

Within this work, these three processes are discussed for four different steel grades that were sintered in the temperature range of $700-1300{ }^{\circ} \mathrm{C}$, in order to investigate the effect of the sintering temperature on the development of the sintered properties of PM steels. For material preparation, in addition to the traditional method of adding elemental powder to mixes, which was used to produce two steels in the Fe-C and Fe-Cu-C systems, one pre-alloyed powder and one grade admixed with an Mn-Si masteralloy powder also were used to prepare two steels that contain oxygen-sensitive elements.

\section{Materials and Methods}

Two grades of water atomized ferrous powders were used as a base powder, a plain iron powder (ASC100.29), and a Cr-Mo pre-alloyed powder Astaloy CrM (see Table 1), both supplied by Höganäs AB, Sweden. Carbon was introduced as natural graphite (grade UF4, Kropfmühl), and copper was of electrolytical type, which was sieved to the dimensional size $<20 \mu \mathrm{m}$. The masteralloy used in this research was H46 produced by Ultra HighPressure Water Atomization, sieved below $20 \mu \mathrm{m}$. The powder was supplied by Atomising Systems Ltd., UK; the chemical composition is given in Table 2 and the particle size distribution in Table 3. Table 4 shows the designations and composition of the prepared mixes. The powders were dry blended in a tumbling mixer for $60 \mathrm{~min}$. Charpy bars (ISO 5740) were pressed for this study in a tool with floating die at $600 \mathrm{MPa}$, with die wall lubrication being afforded (using Multical sizing fluid). Sintering of the samples was performed in a SiC rod heated electrical laboratory furnace equipped with a gas-tight Kanthal APM superalloy muffle at temperatures varying in the range of $700-1300{ }^{\circ} \mathrm{C}$ (interval $100{ }^{\circ} \mathrm{C}$ ) for $1 \mathrm{hr}(\mathrm{dwell}$ time in the high temperature zone) under plain Ar (99.999 quality). After the isothermal holding period at the desired temperature, the samples were cooled in a water-jacketed exit zone under the same protective atmosphere that was used for the sintering.

Table 1. Nominal chemical composition of the base powders used in this study (wt $\%)$ [8].

\begin{tabular}{cccccc}
\hline & Fe & Cr & Mo & C & O-Total \\
\hline ASC100.29 & balance & & & $<0.01$ & 0.08 \\
\hline Astaloy CrM & balance & 3.00 & 0.50 & $<0.01$ & 0.15 \\
\hline
\end{tabular}


Table 2. Chemical composition of the masteralloy used (wt.\%).

\begin{tabular}{cccccccccc}
\hline Name & Fe & Mn & Si & Cr & Cu & Ni & C & O \\
\hline H46 & balance & 39.9 & 7.6 & 0.7 & 0.2 & 0.1 & 0.48 & 2.18 \\
\hline \multicolumn{10}{c}{ (Data obtained by XRF, C and O by LECO). }
\end{tabular}

Table 3. Particle size of the masteralloy used [9].

\begin{tabular}{cccc}
\hline Name & $\mathbf{d}_{10}$ & $\mathbf{d}_{50}$ & $\mathbf{d}_{90}$ \\
\hline H46 & 2.33 & 6.7 & 16.1 \\
\hline
\end{tabular}

Table 4. Material composition of mixes in wt.\% (in brackets: alloy element content).

\begin{tabular}{ccc}
\hline & Designation & Mix Composition \\
\hline 1 & Fe-0.8C & ASC100.29+0.8\%C (0\%) \\
\hline 2 & Fe-2Cu-0.8C & ASC100.29+2\% Cu + 0.8\% C (2\%) \\
\hline 3 & Fe-4MA-0.8C & ASC100.29+4\% MA+ 0.8\% C (1.94\%) \\
\hline 4 & Fe-3Cr-0.5Mo-0.8C & Astaloy CrM + 0.8\%C (3.5\%) \\
\hline
\end{tabular}

The oxygen content was measured through hot fusion analysis using a LECO TC 400 analyzer. Carbon analysis was performed on a LECO CS-230 combustion analyzer. For these purposes, the samples were cut into small pieces of $0.3-0.6 \mathrm{~g}$. A simultaneous thermal analyzer $(\mathrm{STA}=\mathrm{DTA}+\mathrm{TG})$ Netzsch 449 linked to a quadrupole mass spectrometer, Netzsch Aeolos, through a heated capillary was used in order to detect gaseous specimens generated during sintering. Heating rate was $20 \mathrm{~K} \cdot \mathrm{min}^{-1}$, and the maximum temperature was $1300{ }^{\circ} \mathrm{C}$ in $\operatorname{argon}$ atmosphere. Crushed compacts were used as test specimens in this case.

Characterization of the sintered specimens included measuring the density through water displacement, Charpy impact testing of the unnotched specimens at room temperature (ISO 5754), Vickers macrohardness testing HV30, and standard metallographic and fractographic investigations. The electrical resistivity of the sintered compacts (R) was examined at RT by a 4-point method via Ohm's law, and then the specific electrical conductivity was calculated. For measurement of the coercive force HcJ, a 'Foerster-Koerzimat $1096^{\prime}$ was used, and the measurements were performed on samples cut to cuboid shape $\left(10^{*} 6^{*} 3 \mathrm{~mm}\right)$ with the magnetizing field of $200 \mathrm{kA} / \mathrm{m}$.

\section{Results}

Compactibility is always a main property for pressed and sintered ferrous PM parts because almost all the mechanical properties of the sintered part depend on the as-sintered density, and since the parts hardly densify during sintering-in order to retain geometrical precision-, this means the green density [10]. In addition, there is evidence that shows that the green density plays a major role in the deoxidation process and resulting carbon dissolution during sintering of PM steels [11]. The green density values of the four steels studied here are shown in Figure 1, both as absolute and relative values (for the latter, the rule of mixture has been applied to obtain the pore-free density). This shows that after compaction at $600 \mathrm{MPa}$, the green density of plain carbon steel is $7.13 \mathrm{~g} / \mathrm{cm}^{3}$. Adding $2 \%$ copper increased the density to $7.17 \mathrm{~g} / \mathrm{cm}^{3}$, which is in good agreement with the results of some previous studies that showed a positive effect of copper on the compactibility of powders [12-14]. However, part of this effect can be due to the higher theoretical density of Fe-2Cu-0.8C compared with Fe-0.8C as well. The decrease of the green density to $7.08 \mathrm{~g} / \mathrm{cm}^{3}$ by adding $4 \%$ MA reveals a slightly negative effect of this additive on compactibility. It seems that the soft and dendritic $\mathrm{Cu}$ particles could be pressed quite easily and fill the pores between the iron particles, while the near-spherical MA particles with a higher hardness are more difficult to press. The figure also shows that the CrM based mix has the lowest compactibility $\left(6.92 \mathrm{~g} / \mathrm{cm}^{3}\right)$. This is not surprising because it is 
well known that introducing alloying elements such as $\mathrm{Cr}$ and Mo into the iron lattice, as in the case of pre-alloying, increases the strength and hardness of steels by solid solution hardening $[15,16]$ and leads to lower compactibility of the powder.

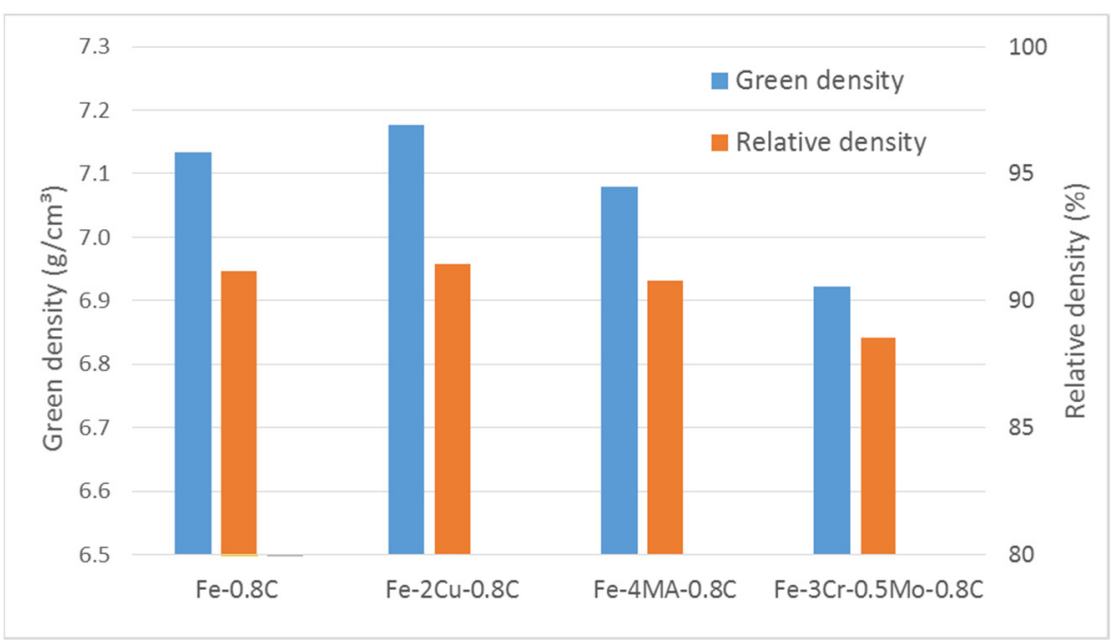

Figure 1. Green and relative density of steel powder mixes compacted at $600 \mathrm{MPa}$ in lubricated die.

\subsection{Study of the Degassing and Reduction Behavior}

Removing the oxides from the surface of the powder particles is critical for successful sintering, otherwise metal-metal contacts and the resulting formation of diffusion bridges during sintering are inhibited. Removal of oxygen from the powder surfaces can occur either through the desorption of water, by decomposition of hydroxides, or, most importantly, by reduction of oxides. In the absence of reducing atmosphere, the reducing agent is carbon, which is usually present in the green compacts as admixed natural graphite. In this condition, prominent reactions are [17]:

$$
\begin{gathered}
\mathrm{MeO}+\mathrm{CO}=\mathrm{Me}+\mathrm{CO}_{2} \text { (indirect carbothermal reduction) } \\
\mathrm{MeO}+\mathrm{C}=\mathrm{Me}+\mathrm{CO} \text { (direct carbothermal reduction) }
\end{gathered}
$$

And when $\mathrm{CO}, \mathrm{CO} 2$ and $\mathrm{C}$ are present, also

$$
\mathrm{C}+\mathrm{CO}_{2}=2 \mathrm{CO} \text { (the Boudouard reaction) }
$$

Therefore, studying the degassing and deoxidation behavior of the material during the thermal process is useful to assess the reduction reactions and the evolution of the sintering process. For this purpose, thermogravimetry/differential thermal analysis (TG/DTA) combined with mass spectrometry (MS), which is a well-known technology for the monitoring of the degassing processes [7,17-19], was used in this work. The results of the measurement are given in Figure 2. Fe-C is the least oxygen sensitive steel in this study, and it was used as a reference to observe the carbothermal reduction of iron oxides. As can be seen, Fe- $0.8 \mathrm{C}$ and $\mathrm{Fe}-2 \mathrm{Cu}-0.8 \mathrm{C}$ show very similar degassing behavior. It is obvious that the addition of $\mathrm{Cu}$ did not cause any change on the typical reduction reactions observed for Fe- $0.8 \mathrm{C}$ powders. This is because the copper forms oxide with thermodynamic stability lower than that of iron, i.e., they are more easily reduced. In the graphs, the most prominent signal is mainly related to the release of carbon monoxide (red curve, mass $28=\mathrm{CO}$ ). Two reduction peaks are visible for these systems, one is a rather narrow peak in the temperature range of $700-800{ }^{\circ} \mathrm{C}$, indicating the carbothermal reduction of the surface oxides. The second peak is markedly broader and took longer, with the maximum being around $1100{ }^{\circ} \mathrm{C}$, and it has been attributed to the reduction of the internal oxides and those enclosed in the pressing contacts, which are more difficult to remove since the oxygen has to diffuse to the surface before it can be removed as gaseous species [17]. For both reduction processes, 
the main product is $\mathrm{CO}$ (resulting from reactions 2 and 3) as is evident from the red curve. The characteristic double peak at high temperature in case of $\mathrm{Fe}-\mathrm{Cu}-\mathrm{C}$ is related to the formation of transient liquid phase in this material at about $1080{ }^{\circ} \mathrm{C}$.
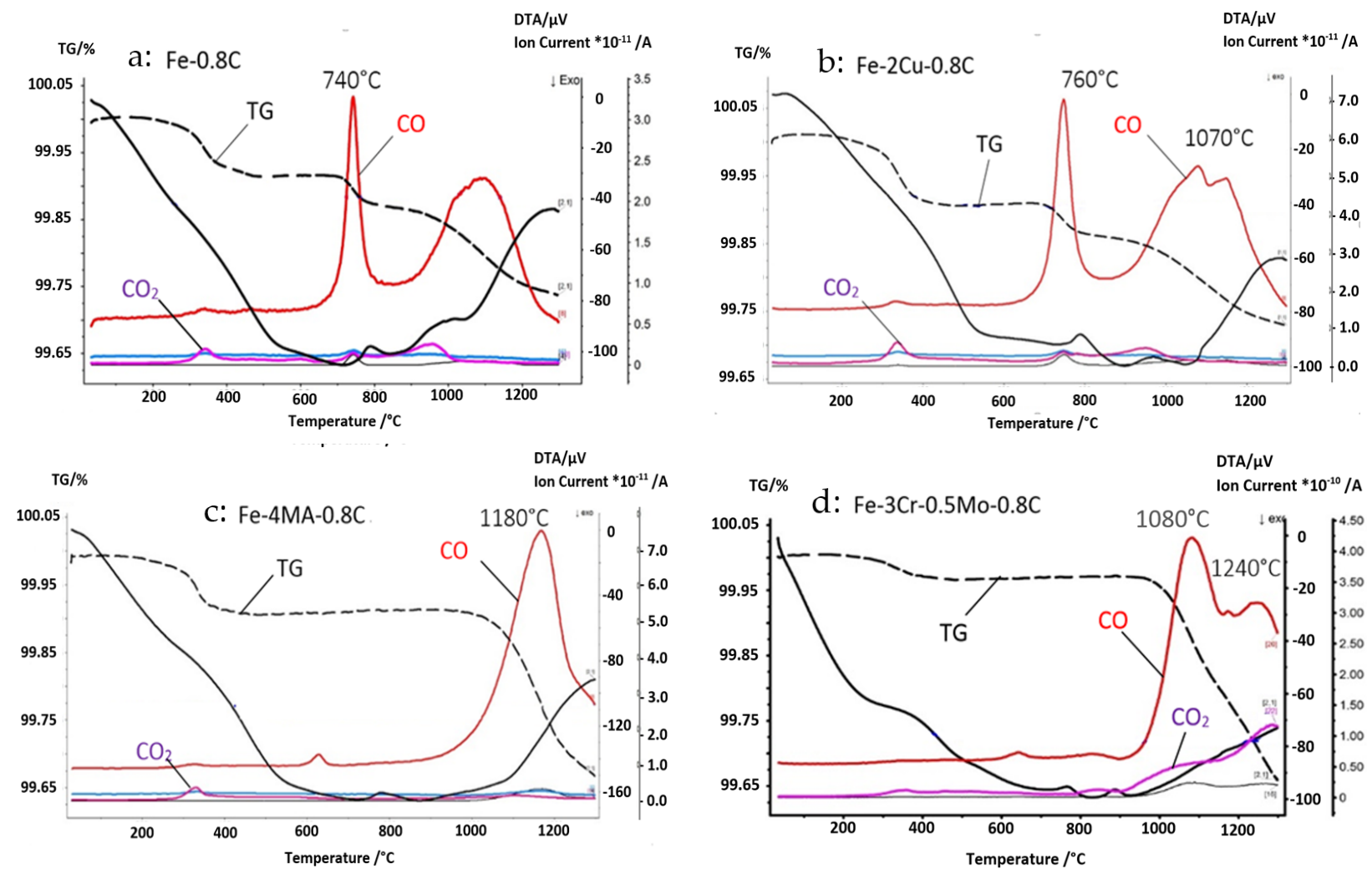

Figure 2. DTA/TG graphs with $\mathrm{MS}$ for different steels, heating rate $20 \mathrm{Kmin}^{-1}, \mathrm{~T}_{\max }=1300{ }^{\circ} \mathrm{C}$, argon. (a) Fe-0.8\%C; (b) Fe-2\%Cu-0.8\%C; (c) Fe-4\%MA-0.8\%C; (d) Fe-3\%Cr-0.5\%Mo-0.8\%C. (a)-(c) mixed; (d) prealloyed.

In Fe-4MA-0.8C, despite using the same base powder (ASC100.29) as for the plain carbon steel, virtually no $\mathrm{m} 28$ peak related to reduction of iron oxides is evident in the range of $700-800{ }^{\circ} \mathrm{C}$, and as can be seen, the carbothermal oxygen removal is shifted to significantly higher temperatures, with the maximum at $1180{ }^{\circ} \mathrm{C}$. This process is also confirmed by TG analysis. In this case, elimination of the peak in the range of $700-800{ }^{\circ} \mathrm{C}$ can be explained by an oxygen transfer process that is called the "Internal Getter" effect. This was observed previously in the sintering of steels containing admixed highly oxygen affine elements, such as chromium or manganese [20]. The process is an oxygen transfer (or migration) from the element with lower oxygen affinity (Fe) to the other element(s) with higher oxygen affinity, such as $\mathrm{Mn}, \mathrm{Cr}$, or $\mathrm{Si}$, the reason being that the atmosphere that is generated by carbothermal reduction of iron oxides is strongly oxidizing for the alloy elements. In this case, due to the introduction of elements with a higher oxygen affinity than Fe (Mn and Si) through the masteralloy, the Internal Getter effect would be expected. Oxygen is transferred through the gas phase from the iron particles (ASC 100.29) to the adjacent MA particles that contain manganese and silicon. The oxides thus formed in the masteralloy require much higher temperatures to be reduced.

In the chromium-molybdenum pre-alloyed steel, similar to the MA steel, no pronounced $\mathrm{m} 28$ peak is observed up to $1000{ }^{\circ} \mathrm{C}$. Karamchedu et al. [21] already showed that the surface of chromium pre-alloyed powder is covered by a heterogeneous oxide layer, a mix of thin iron oxide layer and some more stable oxide ( $\mathrm{Cr}$ rich) islands. Therefore, in this case, a reduction peak at medium temperature was expected for the reduction of iron oxide, which was not observed. In that context, Danninger et al. [17] have already shown that a transformation of the surface iron oxides towards more stable types can occur at 
temperatures between $600-700{ }^{\circ} \mathrm{C}$ when sintering is done in an inert atmosphere (Ar). This changes the surface chemistry of the particles, with the particles being covered with more stable oxides. Therefore, according to these findings, effective oxide reduction and sintering would not be expected in an inert atmosphere below $1000{ }^{\circ} \mathrm{C}$, which is also supported by the results given in [1]. The consequence is that if oxygen-affine alloy elements are introduced either as masteralloys or through pre-alloying, respectively, in both cases high sintering temperatures, typically $>1200{ }^{\circ} \mathrm{C}$, are required to obtain effective oxygen removal, although the effect of residual oxygen on the mechanical properties can be quite different, as will be shown below.

\subsection{Influence of the Temperature on Formation of Sintering Contacts}

The ISO definition of the sintering is: "The thermal treatment of a powder or compact at a temperature below the melting point of the main constituent, for the purpose of increasing its strength by bonding together of the particles" [22]. This definition implies that the formation of bonds or contacts between the particles during the sintering is the main mechanism for the mechanical strength of a PM material. A well-known method to observe the formation and development of these interparticle bridges is fractography of the sintered components [23]. This method was used in the present work for evaluating the sintering progress. In order to give a representative overview, images at $800 \times$ magnification are shown; to reveal the specific features of different broken contacts, selected fracture surfaces are also shown at higher magnification. The effect of the sintering temperature on the fracture surface of the Fe- $0.8 \mathrm{C}$ is shown in Figure 3 (the specimens were broken at room temperature); here the impact energy values and the oxygen contents are also given. In the fracture surface of the steel sintered at $700{ }^{\circ} \mathrm{C}$, the short lines and points (white arrows) on the surfaces of the original powder particles are the first signs of the bond formation. It indicates that, as soon as the surface oxides are removed in the range of $700-800{ }^{\circ} \mathrm{C}$, the first sintering contacts are formed. However, due to low sintering temperature as well as incomplete reduction of surface oxides, these contacts seem negligible. At $900{ }^{\circ} \mathrm{C}$, the oxygen content is reduced by about $25 \%$ compared to $700{ }^{\circ} \mathrm{C}$, and a developed network of lines is discernible with an interparticle ductile dimple fracture (indicated by red arrows) as a consequence of reduction of the surface oxides and higher atomic diffusion, see also the image at higher magnification. At $1100{ }^{\circ} \mathrm{C}$, in addition to the dimple ductile pattern, some transgranular cleavage facets with a river pattern (blue arrows) are also visible, which became coarser at $1300{ }^{\circ} \mathrm{C}$, see also Figure 4 the image at $2000 \times$ magnification. In general, fractographs of specimens sintered at higher temperatures show stronger interparticle bonding and a higher amount of cleavage facets, with coincides with higher impact energy. It indicates that these micromechanisms are not always linked to the macroscopic ductility of PM materials. It can rather be concluded that the better impact properties at higher temperatures are a consequence of the stronger sintering contacts, and the appearance of the fracture surfaces, especially ductile rupture vs. cleavage, is not necessarily an indicator for the macroscopic mechanical properties since, in case of sintered steels, cleavage fracture indicates that the sintering contacts are sufficiently strong to enable fracture also to the cores of the original powder particles.

As mentioned before, in the sintering of metallic components not only sufficient temperature but also removal of surface oxides are essential conditions for atomic diffusion and formation of sintering bridges. This issue would be even more important when we use alloying systems that contain elements with higher oxygen affinity (such as $\mathrm{Cr}, \mathrm{Mn}$, and $\mathrm{Si}$ ), which form more stable oxides that can affect the sintering process. 

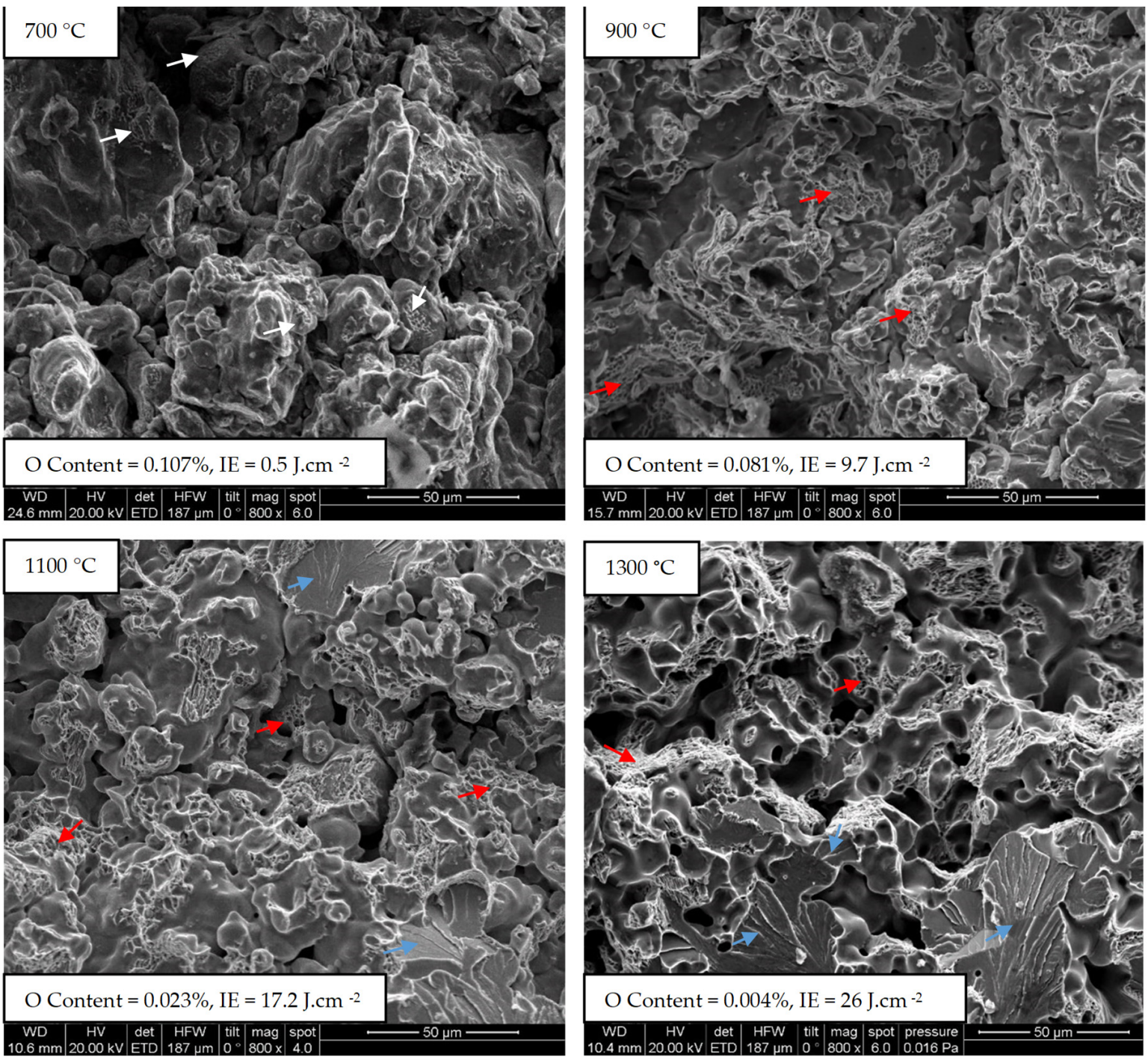

Figure 3. Effect of sintering temperature on morphology of interparticle necks and fracture facets of plain carbon steel $(\mathrm{Fe}-0.8 \% \mathrm{C})$, broken by Charpy impact testing at RT, $800 \times$.
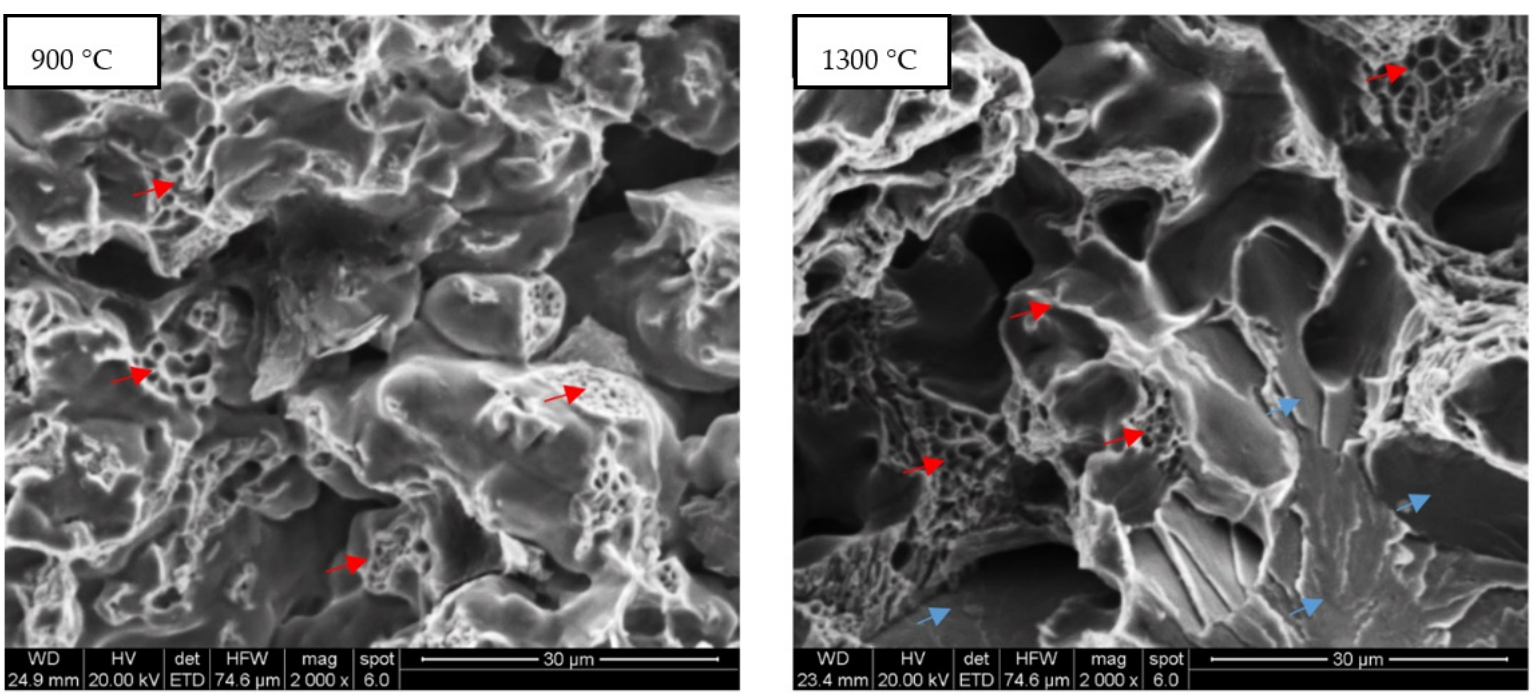

Figure 4. Dimple ductile (red arrows) and transgranular cleavage facets (blue arrows) in fractographs of $\mathrm{Fe}-0.8 \mathrm{C}$, sintered at different temperatures, broken by Charpy impact at RT, $2000 \times$. 
In order to investigate the effect of copper melting, which occurs at around $1085{ }^{\circ} \mathrm{C}$, and the resulting transient liquid phase on the fracture surface, the fracture surfaces of Fe-2Cu-0.8C, sintered at 900 and $1100{ }^{\circ} \mathrm{C}$, before and after formation of the liquid phase, respectively, are shown in Figure 5. As can be seen at $900{ }^{\circ} \mathrm{C}$, an interparticle ductile mechanism is visible in the micrograph, which is rather similar to the Fe-C system. It indicates that the solid-state sintering and resulting fracture surface at this temperature is not influenced significantly by the presence of $\mathrm{Cu}$. However, it is not surprising since, as already shown, almost the same deoxidation processes occur.
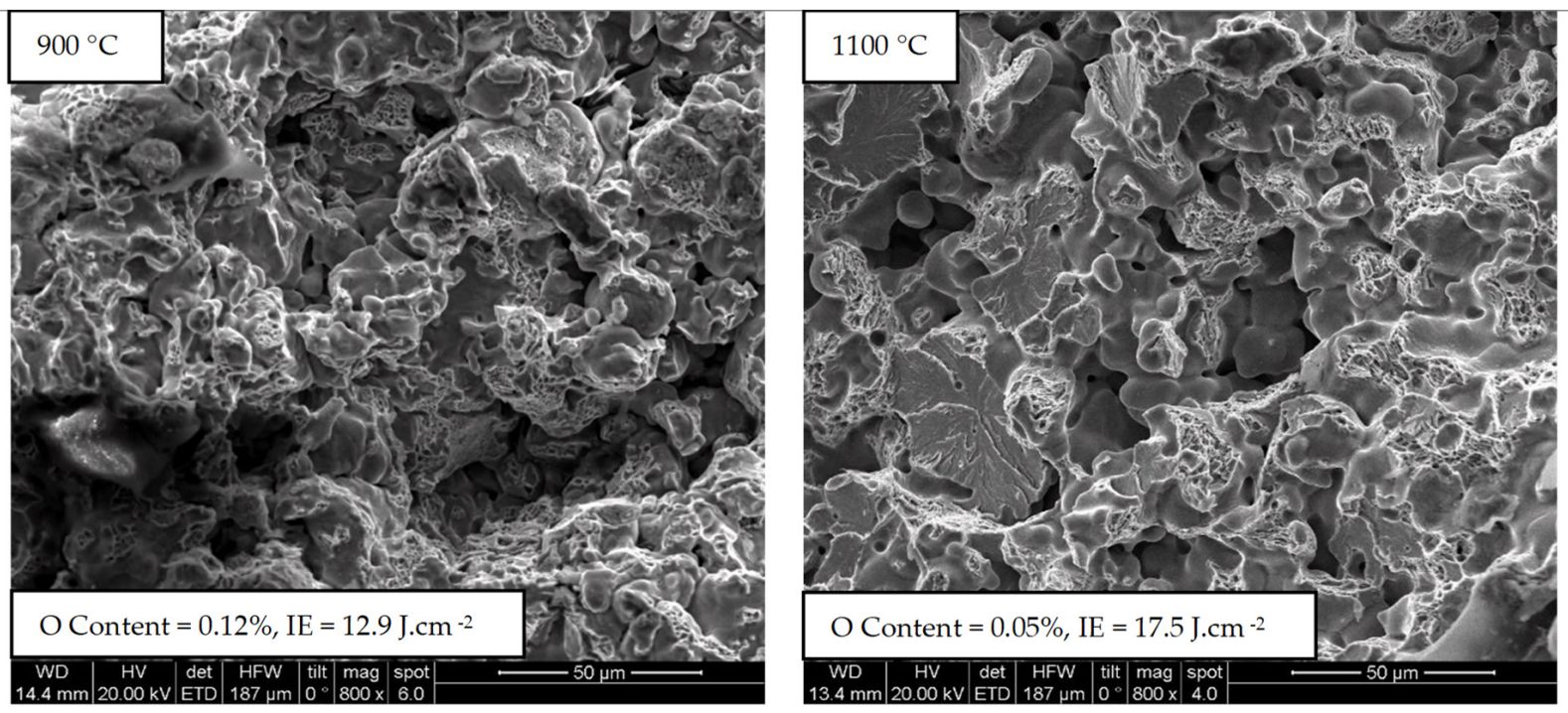

Figure 5. Effect of sintering temperature and transient liquid phase on morphology of interparticle necks and fracture facets of carbon steel including copper $(\mathrm{Fe}-2 \% \mathrm{Cu}-0.8 \% \mathrm{C})$, broken by Charpy impact testing at RT, $800 \times$.

At $1100{ }^{\circ} \mathrm{C}$, the transient liquid phase sintering is a consequence of the melting of copper [24]. The fracture surface for this temperature shows transgranular cleavage facets, which are the results of stronger sintering contacts between the particles. Generally, in liquid phase sintering, high diffusion rates are associated with liquids, resulting in fast sintering due to higher mobility of the atoms, which usually leads to form stronger contacts [25]. In this case, however, the fracture surfaces, as well as the shape of the pores, do not show any significant difference to $\mathrm{Fe}-\mathrm{C}$, and as can be seen, the impact energy of Fe-C and Fe-Cu-C is almost identical (see Figures 3 and 5, at $1100^{\circ} \mathrm{C}$ ). One possible reason for this could be related to the copper swelling phenomenon, a process by which molten copper penetrates the boundaries between the individual iron particles and pushes them away, which leads to lower density. As a result, despite the formation of liquid phase and thus accelerated sintering process, the sintering contacts are not as large as expected. On the other hand, the significantly higher hardness of the $\mathrm{Cu}$ alloyed type (see below, Figure $8 \mathrm{f}$ ) can also be expected to adversely affect the impact energy.

Figure 6 shows the fracture surfaces of two steels containing elements with higher oxygen affinity, Fe-3Cr-0.5Mo-0.8C (pre-alloyed) and Fe-4MA-0.8C (mixed), both after sintering in the temperature range of $900-1300{ }^{\circ} \mathrm{C}$. At $900^{\circ} \mathrm{C}$, in Fe-4MA-0.8, the formation of sintering contacts is quite noticeable, while the fractograph of Astaloy CrM shows hardly any sign of sintering between the particles. This could be a good explanation for the low impact energy of Astaloy CrM $\left(0.5 \mathrm{~J} \cdot \mathrm{cm}^{-2}\right)$ at this temperature, while the masteralloy steel, despite having almost the same amount of oxygen, shows better sintering behavior with the impact energy of $8.6 \mathrm{~J} \cdot \mathrm{cm}^{-2}$, which is fairly close to that of $\mathrm{Fe}-0.8 \% \mathrm{C}$. This indicates that the presence (or formation) of oxide layers on the chromium pre-alloyed particles prevented contact formation, while in the masteralloy system, despite having rather high oxygen content, transferring (removing) oxygen from the ASC100.29 particles to the masteralloy 
particles provided a favorable condition for formation of sintering contacts between the iron particles. This underlines that not only the total oxygen content but also the distribution plays a major role in the mechanical properties.

Fe-4MA-0.8C
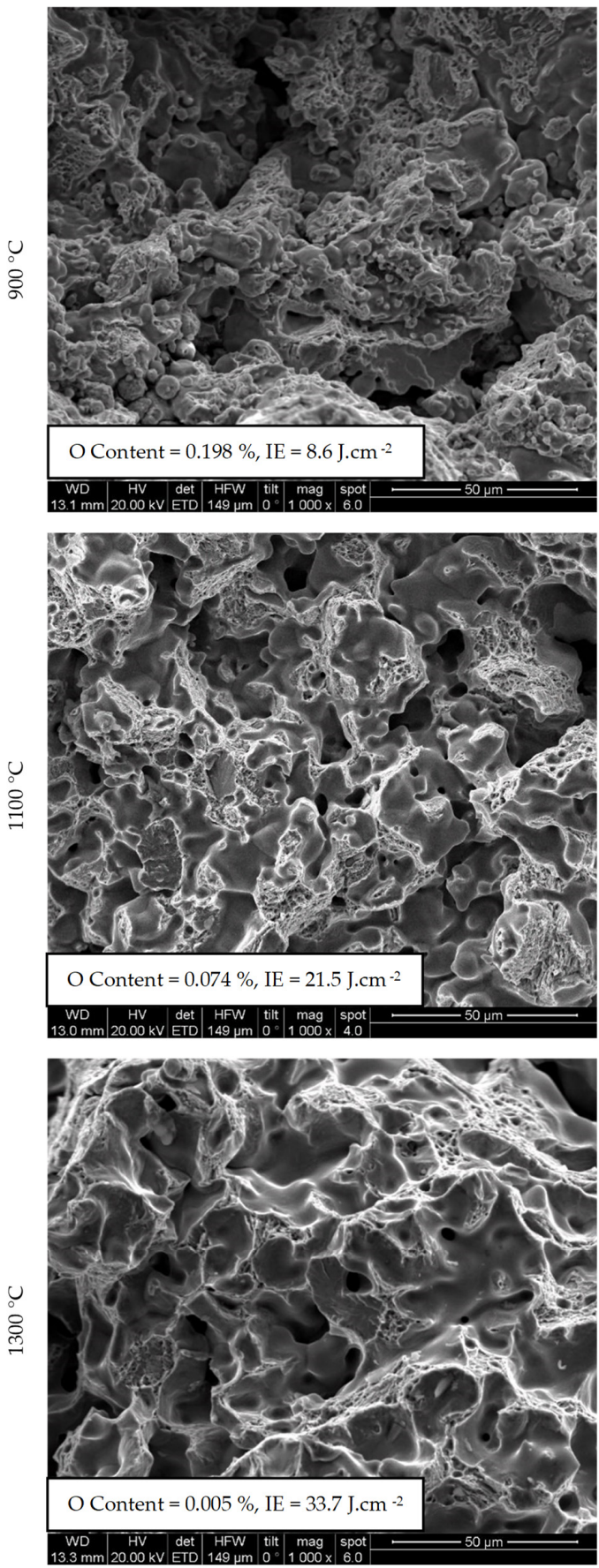

Fe-3Cr-0.5Mo-0.8C
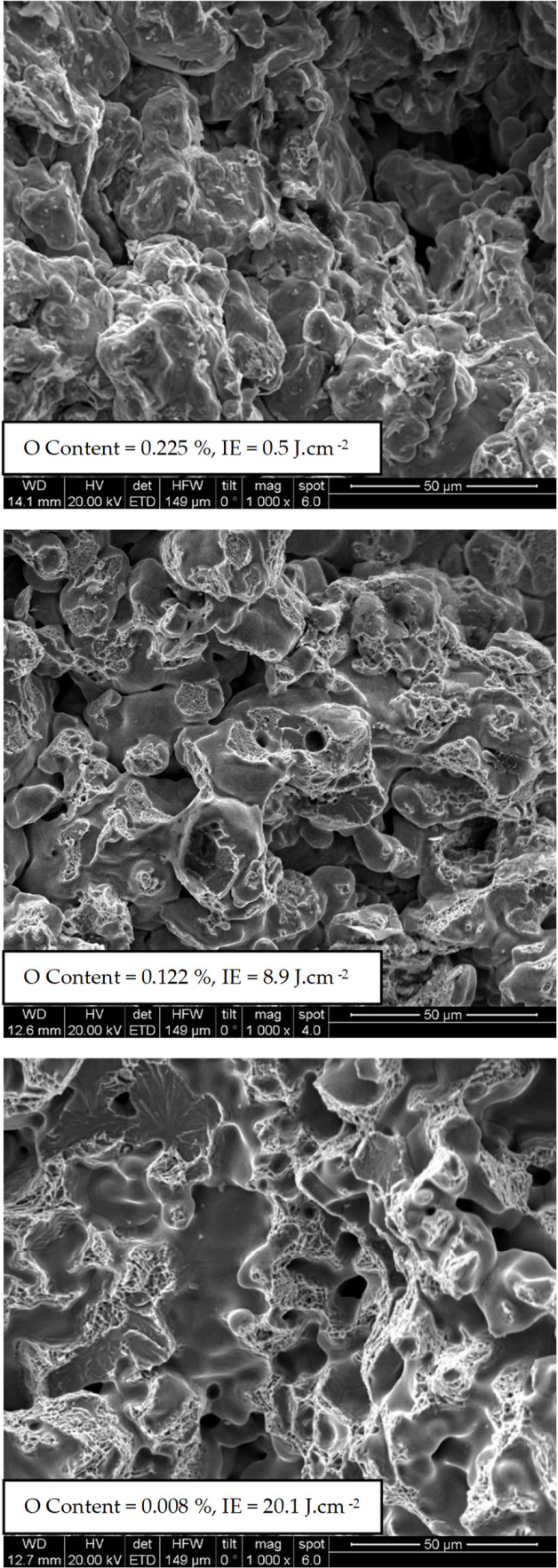

Figure 6. Effect of sintering temperature on the morphology of the interparticle necks and fracture Figure $1000 \times$.

At $1100{ }^{\circ} \mathrm{C}$, more developed bonds are visible for both steels. At this temperature, the MA steel shows a rather higher sintering activity, with a transgranular dimple fracture and stronger sintering contacts, while in the case of Astaloy CrM sintering has proceeded less, and the original particles kept more or less their original shapes with a fracture mechanism of mostly dimple pattern of the interparticle necks. The presented values for the oxygen content at $1100{ }^{\circ} \mathrm{C}$ indicate that oxygen removal is more pronounced in the MA 
steel, which could be a reason for its higher sintering activity and higher impact energy, together with the concentration of oxygen on the MA particles. At $1300^{\circ} \mathrm{C}$, growth of the sintering contacts and reduction of the oxygen content resulted in the maximum impact toughness for both steels. However, this progress in the properties at $1300{ }^{\circ} \mathrm{C}$ was more pronounced for Astaloy CrM than for the masteralloy steel. In other words, sintering at higher temperature is more effective for achieving the full capability of the pre-alloyed Cr-Mo steel, which confirms the findings of Kremel et al. [1].

\subsection{Metallography and Microstructures}

A further useful method for characterizing the sintering of PM steels is metallographic examination. Investigations of sintering phenomena, such as the disappearance of boundaries between the individual particles, dissolution of carbon, and the distribution and diffusion of alloy elements, as well as the morphology of pores are possible with this method [26,27]. Figure 7 shows the characteristic microstructures of the investigated steels sintered at different temperatures. After sintering at $700{ }^{\circ} \mathrm{C}$, in all steels the boundaries between the main powder particles are visible, without any sign of sintering or dissolution of alloying elements. At $900{ }^{\circ} \mathrm{C}$, micrographs of Fe- $0.8 \mathrm{C}$ show pearlite formation, indicating a partial carbon dissolution at this temperature, which is increased at higher sintering temperature, reaching a maximum at $1100{ }^{\circ} \mathrm{C}$ and remaining almost without significant change at $1300{ }^{\circ} \mathrm{C}$.

In Fe-2Cu-0.8C, below $1100{ }^{\circ} \mathrm{C}$, the presence of the red copper particles in the microstructure is the main difference to the microstructure of Fe- $0.8 \mathrm{C}$, which shows that dissolution of this alloying element in the iron lattice through solid state diffusion was not significant below the melting point of $\mathrm{Cu}\left(1085^{\circ} \mathrm{C}\right)$, while above this threshold no copper particle is visible. It is well known that, above the $\mathrm{Cu}$ melting point, a transient liquid phase mechanism is active [28,29]. Elimination of the $\mathrm{Cu}$ particles from the microstructure and fairly homogeneous distribution of $\mathrm{Cu}$ show that this homogenization mechanism is much more effective compared with solid state mechanism. Another result of transient liquid phase in such systems is the presence of secondary pores $[7,24,30]$. Since the melt spreads into the pores and pressing contacts of the matrix, it leaves pores behind, the diameters of which are correlated to the size of the respective original alloy element particles. However, due to the use of fine copper powder $(<20 \mu \mathrm{m})$, with dendritic shape in the current work, distinguishing such pores from the primary porosity originating from the green compact seems to be difficult since there is virtually no difference in size.

In the steel alloyed with the masteralloy, at $900{ }^{\circ} \mathrm{C}$ the boundaries between the particles start to disappear and pearlite formation is also visible, as a consequence of carbon dissolution. These observations indicate removal of the oxides from the surface of the plain iron particles at a rather low temperature. This confirms the hypothesis of oxygen transfer from the surface of iron particles to the masteralloy particles, i.e., in fact a metallothermic reduction of the Fe powder surfaces. At this temperature, in addition to pearlite formation, a darker-etched rim in the surface region of all particles is also visible. Considering the ability of manganese to evaporate and condense on the matrix particles even at moderate sintering temperatures [31], it can be stated that these areas are related to the condensed manganese, which has diffused into the iron lattice for some distance as well. The fully pearlitic microstructure at $1100^{\circ} \mathrm{C}$ indicates that the carbon dissolution process is complete at this temperature. Increasing the sintering temperature to $1300{ }^{\circ} \mathrm{C}$ has resulted in a more uniform distribution of the alloying elements; the darker rims have disappeared.

In the $\mathrm{Cr}$ alloy steel, unlike the other grades, at $900^{\circ} \mathrm{C}$ the boundaries are still clearly visible in the microstructure. This is not surprising since Kremel et al. [1] have shown that at this temperature the Cr-Mo steel is particularly prone to oxygen pickup from the atmosphere. Furthermore, only minor signs of carbon dissolution can be seen, confirming that the stable chromium oxides on the powders prevent both carbon dissolution and formation of the sintering contacts, in good agreement with the results of the fractography and impact test. Formation of a bainitic-ferritic microstructure at $1100{ }^{\circ} \mathrm{C}$ indicates that 
carbon dissolution occurred at this temperature. At $1300{ }^{\circ} \mathrm{C}$ compared to $1100{ }^{\circ} \mathrm{C}$, the microstructure shows a pronounced change, presenting some martensitic regions, which suggests that, compared with other steels based on ASC100.29, Astaloy CrM needs a higher temperature for completing the alloying process.
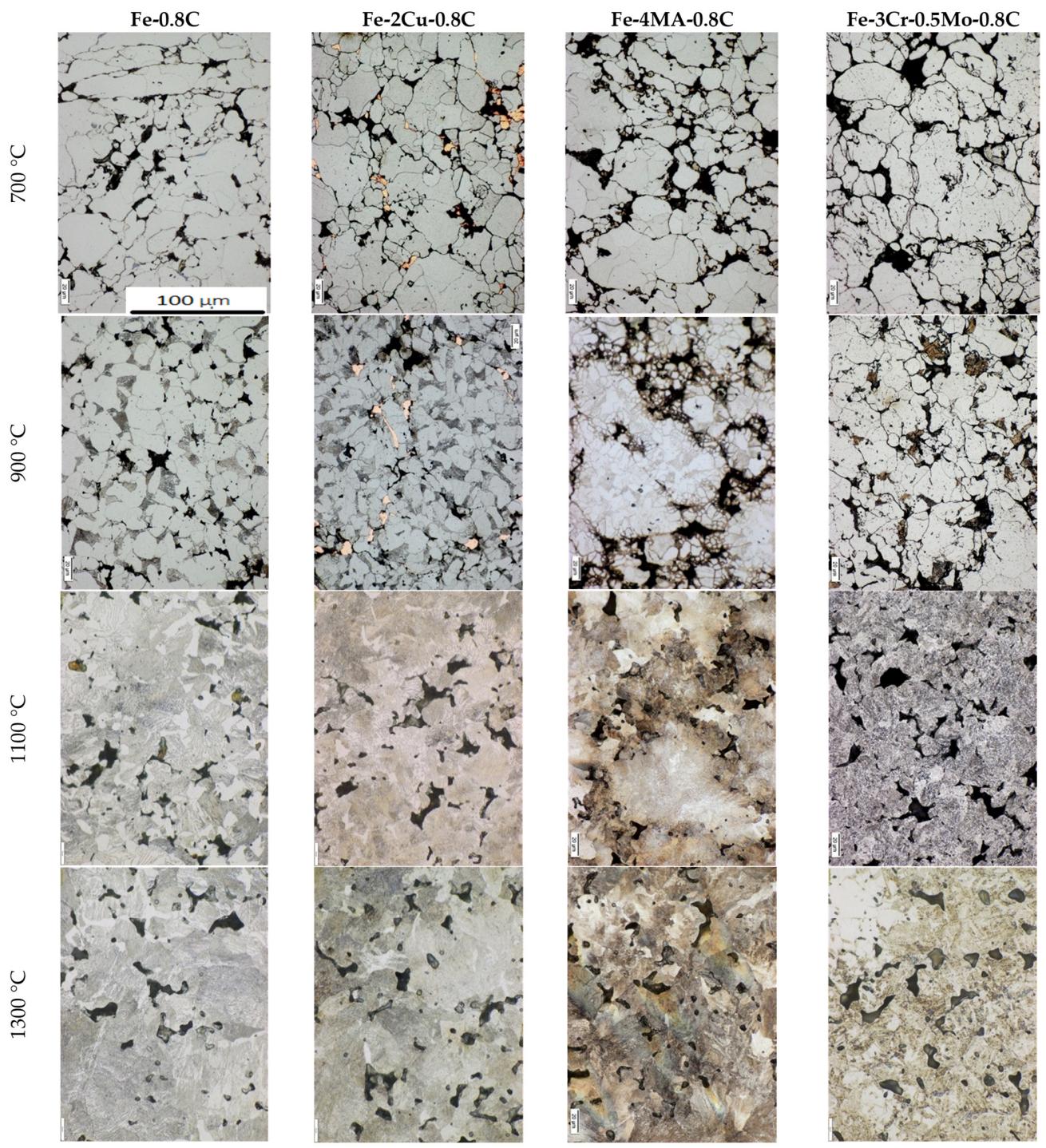

Figure 7. Microstructures of steels sintered $60 \mathrm{~min}$ in argon at different temperatures, $500 \times$ (scale bar in Figure 6a holds for all images).

\subsection{Dimensional and Mechanical Properties as a Function of the Sintering Temperature}

Dimensional change: the dimensional change during sintering of the PM steels is affected by different phenomena; in alloyed systems, it is typically more complex than in plain iron compacts [32]. For instance, incorporation of the carbon atoms into the iron lattice results in a growth in volume [33,34], while some phenomena such as pore elimination and developing of sintering necks could lead to shrinkage, or negative dimensional change. The dimensional changes of the samples as a function of the sintering temperature are presented in Figure 8a. Fe-0.8C shows a gradual expansion from $700-1000{ }^{\circ} \mathrm{C}$, caused by the carbon dissolution, and after this process is completed, shrinkage follows during sintering at the higher temperatures up to $1300{ }^{\circ} \mathrm{C}$. In Fe-2Cu- $0.8 \mathrm{C}$, from $700-1000{ }^{\circ} \mathrm{C}$, the behavior is more or less similar to Fe-C. An upward trend resulting from the dissolution of carbon, and probably of a small amount of $\mathrm{Cu}$, in the solid state is visible. At $1100{ }^{\circ} \mathrm{C}$, the $\mathrm{Cu}$-containing steel revealed a different behavior to $\mathrm{Fe}-\mathrm{C}$, and it showed a significant expansion, which resulted in a reduction in the sintered density (see Figure $8 \mathrm{a}, \mathrm{b}$ ). This also 
might be a reason why the impact energy at $1100{ }^{\circ} \mathrm{C}$ was not higher compared to $1000{ }^{\circ} \mathrm{C}$ (Figure 8f), although the higher hardness, due to solid solution strengthening of the $\mathrm{Fe}$ matrix by $\mathrm{Cu}$, might play a role here (see below). This major expansion in the Fe-Cu-C systems is linked to copper melt formation and is well known as the "copper swelling" effect [7,35-37]. As already stated above, the accepted mechanism of this phenomenon is penetration of liquid copper into iron interparticle boundaries, which solidifies there and causes swelling. Another point that should be mentioned in the Fe-Cu-C system is the role of carbon, which controls and limits the copper swelling by increasing the dihedral angle between the $\mathrm{Cu}$ melt and the iron particles [27,29,33,38]. Above $1100{ }^{\circ} \mathrm{C}$, after completion of carbon and copper dissolution, there follows the usual shrinkage of sintering.

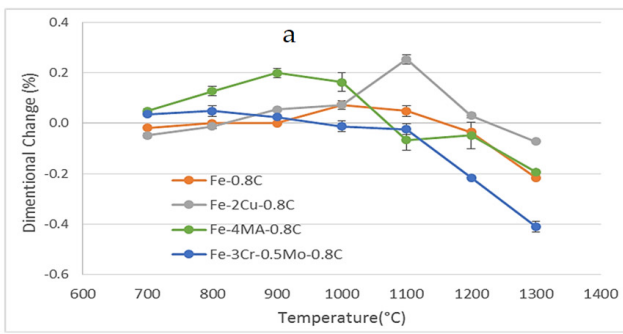

Dimensional change

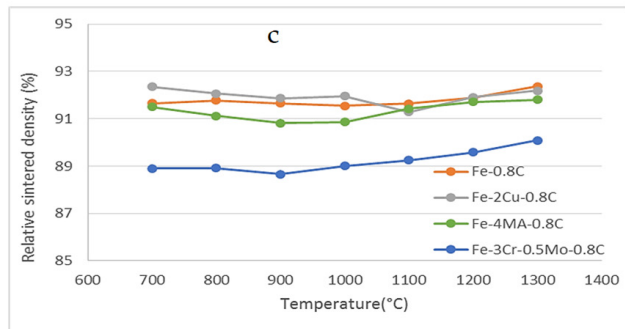

Relative sintered density

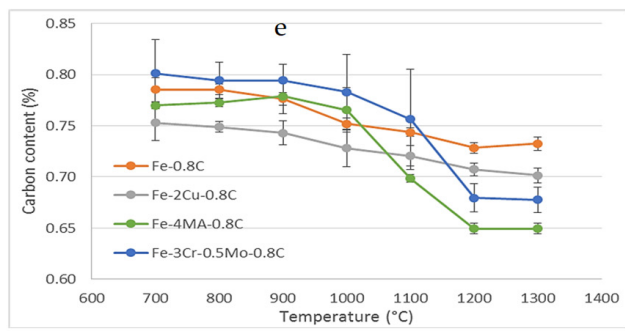

Combined carbon

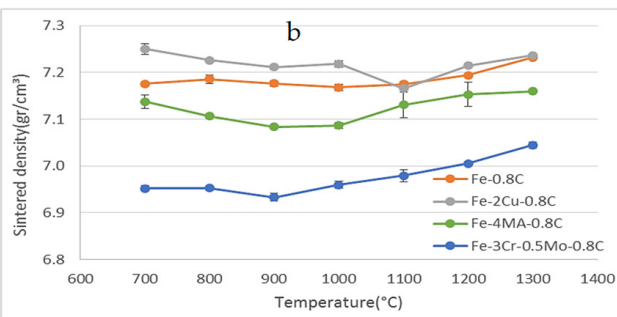

Sintered density

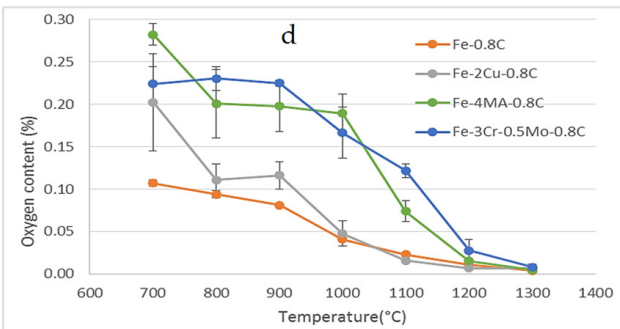

Oxygen content

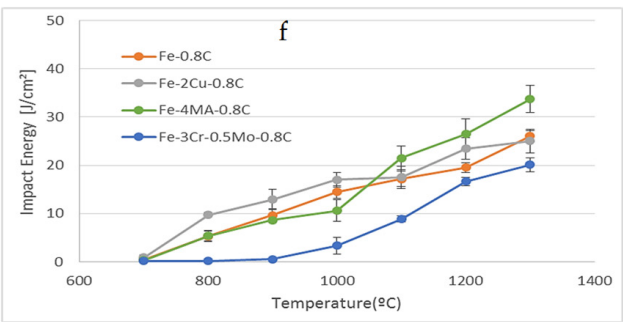

Charpy impact energy

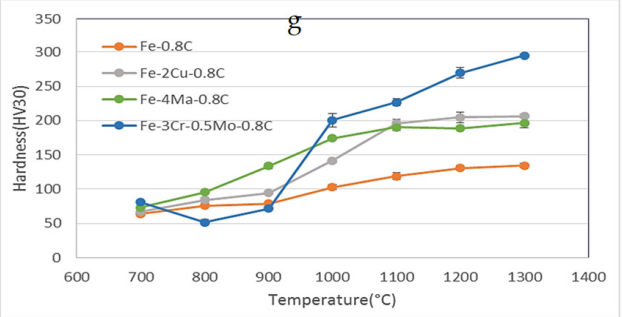

Apparent hardness

Figure 8. Sintered properties of steels compacted at $600 \mathrm{MPa}$ and sintered for $60 \mathrm{~min}$ at different temperatures in Ar. 
In the steel alloyed with the masteralloy, from $700-1000{ }^{\circ} \mathrm{C}$, a more pronounced expansion than with $\mathrm{Fe}-\mathrm{C}$ and $\mathrm{Fe}-\mathrm{Cu}-\mathrm{C}$ is visible. As mentioned already, and shown in [31,39], alloying of PM steels with (admixed) Mn can occur through the gas phase even at fairly low temperature. Therefore, also in this case, the higher expansion can be explained by the diffusion of manganese into the iron lattice in particular at the sintering contacts, causing "Mn swelling" in a similar way as the Cu swelling, however, through the gas phase. At $1100{ }^{\circ} \mathrm{C}$, the masteralloy steel showed a pronounced shrinkage and densification as well as improved impact energy. Elemental analysis also showed a significant oxygen removal from the system. All these results obtained at $1100{ }^{\circ} \mathrm{C}$ revealed that $1100{ }^{\circ} \mathrm{C}$ is apparently a critical sintering temperature for this steel. Above 1100 and up to $1300{ }^{\circ} \mathrm{C}$, the sintering resulted in higher shrinkage and impact energy, as well as in more complete oxygen removal.

In contrast to the other steels, the pre-alloyed Astaloy CrM did not show any trend towards expansion. In the temperature range of $700-900{ }^{\circ} \mathrm{C}$, the dimension was almost constant due to the presence of the stable surface oxides, which prevent carbon dissolution and sintering. At 1000 and $1100{ }^{\circ} \mathrm{C}$, no expansion is visible despite carbon dissolution (metallography, Figure 7). It means that at these temperatures the expansion caused by carbon dissolution is compensated by sintering shrinkage. After sintering at $1200{ }^{\circ} \mathrm{C}$, the $\mathrm{Cr}$ alloy steel showed pronounced shrinkage and densification. The other properties, such as $\mathrm{O} / \mathrm{C}$ contents and impact energy (Figure $8 \mathrm{~d}-\mathrm{f}$ ), show a significant improvement at this temperature. This indicates that, in order to exploit the full potential of this $\mathrm{Cr}$ alloy steel, sintering should be performed at least at $1200{ }^{\circ} \mathrm{C}$.

Hardness: The role of carbon dissolution, as well as of the other alloying elements on the hardness of PM steels, is well known. With regard to the changes in chemistry of the steels due to the dissolution of carbon and metallic alloy elements during sintering, the hardness measurement can be utilized as a useful method for characterizing sintering of the steels at different temperatures. Results of hardness measurements as a function of sintering temperature are presented in Figure $8 \mathrm{~g}$. In general, for three steels, Fe-0.8C, Fe-2Cu-0.8C, and Fe-4MA-0.8C, the graph shows an upward trend in the hardness from $700-1100{ }^{\circ} \mathrm{C}$. As can be seen, the hardness at $1100^{\circ} \mathrm{C}$ is maximum, and further increasing the sintering temperature does not have any significant effect on the hardness.

In $\mathrm{Fe}-0.8 \mathrm{C}$, the carbon dissolution and pearlite formation are the main reasons for the increase of the hardness between $700-1100{ }^{\circ} \mathrm{C}$.

In Fe-2Cu-0.8C, in addition to the carbon dissolution, the effect of $\mathrm{Cu}$ must be considered, which can increase the hardness by solid solution strengthening as well as precipitation hardening. As can be seen, below $1100{ }^{\circ} \mathrm{C} \mathrm{Cu}$ remains solid, and the diffusion into the iron lattice is not significant. The hardness increase is thus more or less similar to Fe- $\mathrm{C}$, i.e., due to carbon dissolution, while after the sintering at $1100{ }^{\circ} \mathrm{C}, \mathrm{Cu}$ melting accelerates the alloying process, resulting in a significant raise in the hardness as a consequence of solid solution hardening.

The masteralloy steel shows a more pronounced upward trend of the hardness in the range of $700-1100{ }^{\circ} \mathrm{C}$ compared to Fe-0.8C. Once again, these results confirm the hypothesis of gas phase transport of manganese to Fe and subsequent diffusion into the iron lattice during the sintering process, which agrees well with the dimensional change. Constant hardness at the temperatures above $1100{ }^{\circ} \mathrm{C}$ suggests that the diffusion of manganese and the alloying process at this temperature are virtually complete.

In the $\mathrm{Cr}$-Mo pre-alloyed steel, no significant change in the hardness is observed at temperatures below $1000^{\circ} \mathrm{C}$, while after sintering at $1000^{\circ} \mathrm{C}$, a significant increase of this property is observed, and this trend continues up to $1300^{\circ} \mathrm{C}$. Similar to the other steels, the reason of increasing hardness for this material with higher sintering temperatures is carbon dissolution and resulting formation of bainite and martensite [40]. However, it seems that this process is delayed until the stable surface chromium oxides have been reduced and thus removed. In contrast to other steels, which do not show significant hardness changes above $1100{ }^{\circ} \mathrm{C}$, Astaloy CrM shows a continuous upward trend up to $1300^{\circ} \mathrm{C}$. A possible 
reason for this could be attributed to the reduction of the chromium oxide phases that occurred at higher temperatures of sintering and, to some degree, also densification, as can be seen in Figure 8b,c. This hardness increase is observed despite the considerably lower $\mathrm{C}$ content after sintering at high temperatures (Figure $8 \mathrm{~g}$ ), caused by $\mathrm{C}$ consumption for carbothermal reduction processes, the high oxygen content of these pre-alloyed powders consume more $\mathrm{C}$ than with $\mathrm{Fe}-\mathrm{C}$ or Fe- $\mathrm{Cu}-\mathrm{C}$. The high hardness, despite fairly low $\mathrm{C}$ content, underlines the effect of the high alloy element content in this material, as indicated in Table 4.

\subsection{Electrical and Magnetic Properties as a Function of the Sintering Temperature}

The electrical conductivity of the steels is presented in Figure 9a. In the initial stages of sintering, the electrical conductivity of steels could be affected by several phenomena. Carbon dissolution and resulting pearlite formation in the iron lattice reduces the electrical conductivity compared to plain iron compacts. The dissolution of alloy elements in the iron lattice also has a negative effect on this property of the material as well. On the other hand, reduction of the surface oxides, neck formation, growth of the sintering contacts, and changes in the shape of pores can increase the conductivity of PM parts during sintering, especially at higher temperatures [41-43]. In Fe-0.8\%C, an increase in the electrical conductivity is visible at $800^{\circ} \mathrm{C}$, attributed to the removal of oxygen from the powder particle surfaces and stress relaxation in the grains [42,43]. At $900{ }^{\circ} \mathrm{C}$, the conductivity does not show significant changes compared to $800^{\circ} \mathrm{C}$, apparently since at this temperature, the positive effect of the neck formation and oxide reduction is compensated by the negative effect of the carbon dissolution. At 1000 and $1100{ }^{\circ} \mathrm{C}$, in which case the carbon dissolution is more complete, a significant decline in the electrical conductivity is visible. These results are also in good agreement with the results of metallography and dimensional change as presented in Figures 7 and 8a. As previously shown, above these temperatures (between 1100-1300 ${ }^{\circ} \mathrm{C}$ ) and after completion of carbon dissolution, sintering results in slight shrinkage, growth of sintering contacts, and thus neck enlargement, which could positively affect the conductivity. However, according to these results compared to low temperatures, less change in electrical conductivity was observed, which agrees with Simchi's results [41] who stated that the most pronounced effects of sintering contact formation and growth occur in the medium temperature range.

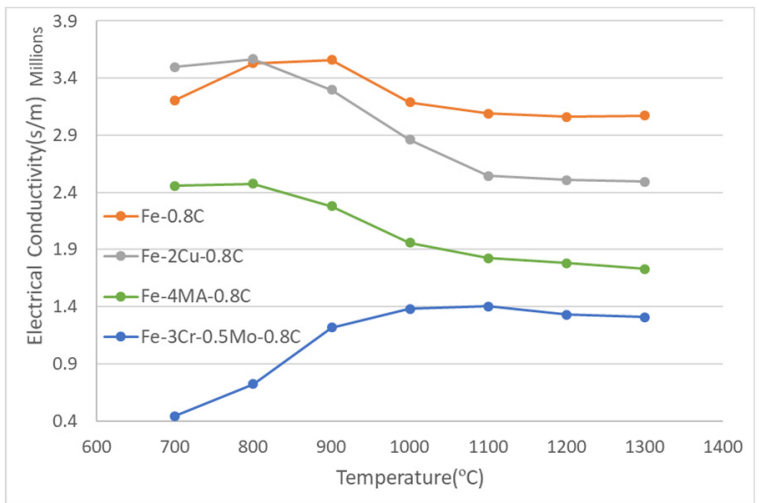

(a) Electrical conductivity

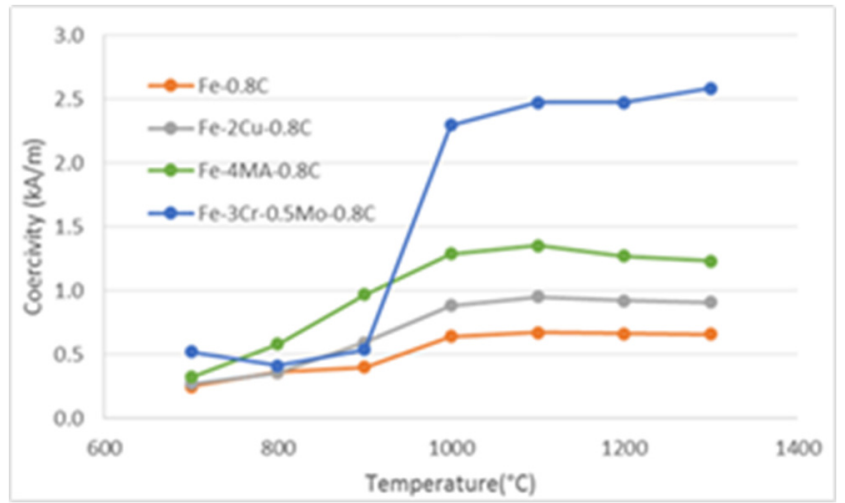

(b) Coercivity

Figure 9. Physical properties of steels compacted at $600 \mathrm{MPa}$ and sintered for $60 \mathrm{~min}$ at different temperatures in Ar.

In the $\mathrm{Fe}-\mathrm{Cu}-\mathrm{C}$ system sintered at $700{ }^{\circ} \mathrm{C}$, the presence of $\mathrm{Cu}$ particles that fill the free spaces between the iron particles (Figure $7, \mathrm{Fe}-\mathrm{Cu}-\mathrm{C}$ at $700{ }^{\circ} \mathrm{C}$ ), resulted in higher conductivity compared to Fe-C. At $800^{\circ} \mathrm{C}$. the results showed that the positive and negative factors compensate each other, and the conductivity remained constant, but above this temperature, between $800-1100{ }^{\circ} \mathrm{C}$, the alloying process was accelerated by higher temperature, and the conductivity started to decrease. As can be seen, dissolution of copper in addition 
to that of graphite resulted in lower conductivity compared to Fe-C. The difference to Fe-C at 900 and $1000{ }^{\circ} \mathrm{C}$, in which case alloying occurred through solid state, is small, while at $1100^{\circ} \mathrm{C}$, after dissolution of all the copper as a consequence of melt formation, a larger difference is evident. Similar to $\mathrm{Fe}-\mathrm{C}$, the electrical conductivity does not show significant changes above $1100{ }^{\circ} \mathrm{C}$ and up to $1300{ }^{\circ} \mathrm{C}$.

In Fe-MA-C, at 700 and $800^{\circ} \mathrm{C}$, lower conductivity values are recorded compared to the two previously mentioned steels, although the same base powder was used. Between $800-1100{ }^{\circ} \mathrm{C}$, a continuous downward trend caused by dissolution of carbon and manganese in the iron matrix is visible in the graph. Above $1100{ }^{\circ} \mathrm{C}$, the conductivity showed less change, which indicates that the alloying process is almost complete at this temperature. These results are also in good agreement with the results of dimensional change and hardness measurement (See Figure 8a,g).

In contrast to the other steels based on plain iron powder, Astaloy CrM does not show any decrease in conductivity due to carbon dissolution or alloying process. An upward trend from $700-1100{ }^{\circ} \mathrm{C}$ is discernible, followed by less changes at 1200 and $1300{ }^{\circ} \mathrm{C}$. This indicates that in this alloying system, the phenomena that have a positive effect on conductivity - reduction of the surface oxide or neck formation-play a more significant role, which masks the negative effect of the carbon dissolution.

Regarding the coercive force, it is well known that this property is influenced by numerous parameters. The most important ones are lattice defects due to mechanical strain (dislocations), grain size of the iron matrix, and the purity of the material. Imperfections, such as dislocations, cause considerable increase of $\mathrm{Hc}$, but they can be eliminated completely by annealing. Analyzing the influence of various parameters on the coercive force of sintered Fe-parts showed that the density is rather insignificant, while size and shape of the pores are much more important than their total volume (density) [44,45]. In addition, it has been shown that the presence of fine non-magnetic inclusions, principally carbides, in ferromagnetic materials such as steels, inhibits the motion of domain walls and results in degradation of the soft magnetic properties [46].

The coercivity values of the steels are presented in Figure $9 \mathrm{~b}$ as a function of the sintering temperature. The effect of carbon dissolution on the coercivity of Fe-C is clearly visible between $700-1000^{\circ} \mathrm{C}$. Above $1000^{\circ} \mathrm{C}$ and after completion of the alloying process, the coercivity showed less changes up to $1300{ }^{\circ} \mathrm{C}$. Compared to Fe-C, in Fe-Cu-C, in addition to the carbon, dissolution of $\mathrm{Cu}$ affected the coercivity as well and resulted in higher values. In Fe-MA-C, the effect of manganese dissolution in the iron lattice is clearly shown by the increase of coercivity from $800-1100^{\circ} \mathrm{C}$, which is in good agreement with the results of the dimensional change and hardness measurement. In Astaloy CrM, finally, the coercivity does not show any significant change at low temperatures up to $900{ }^{\circ} \mathrm{C}$, but at $1000{ }^{\circ} \mathrm{C}$, simultaneously with the removal of surface oxides and carbon dissolution, it showed a considerable jump, which indicates that the effect of carbon dissolution on this property is more significant in Cr-Mo alloyed steel than in the other systems. Furthermore, the comparison with Figure $8 \mathrm{~g}$ clearly shows the distinct, though not perfect, correlation between mechanical and magnetic hardness in particular for this pre-alloyed steel grade.

\section{Summary and Conclusions}

In order to investigate the effect of the sintering temperature on the physical and mechanical properties of PM steels, four different steel grades were sintered in the temperature range $700-1300{ }^{\circ} \mathrm{C}$ in an inert atmosphere (Ar). The conclusions based on the results of the characterizations are as follows:

In the $\mathrm{Fe}-\mathrm{C}$ system, $0.8 \%$ graphite was added to a plain iron powder in order to prepare a plain carbon steel. Formation of first sintering contacts was observed simultaneously with the carbothermal reduction of the surface oxides at $700-800{ }^{\circ} \mathrm{C}$. Increasing the temperature up to $1300^{\circ} \mathrm{C}$ resulted in a continuous reduction of the oxides and growth of the sintering necks between the particles, which improved the impact properties of the steel. Metallographic studies, as well as measurements of dimensional change and hardness, showed 
that the process of carbon dissolution in the iron lattice started from fairly low temperatures at the same time as the reduction of surface oxides occurred, reaching complete dissolution at $1100{ }^{\circ} \mathrm{C}$. The latter process was also observed by measuring the electrical conductivity and coercive force as a function of the sintering temperature. Sintering at further increased temperatures did not show significant effects on the microstructure and hardness as well as electrical conductivity and coercive force, however a marked effect on the impact energy.

For the Fe-Cu-C system, a mixture of iron powder, $0.8 \%$ graphite and $2 \%$ copper was used. The results showed that the presence of $\mathrm{Cu}$ in this system hardly affected the reduction reactions and carbon dissolution process compared to Fe-C. Improvement of mechanical properties (impact and hardness) was observed due to accelerated homogenization of $\mathrm{Cu}$ in the matrix as a consequence of transient liquid phase at temperatures above $1100{ }^{\circ} \mathrm{C}$. However, in this temperature range, copper swelling resulted in a significant expansion and a decrease of the density, therefore, in addition to the increased hardness that can negatively affect the impact properties, the effect of density reduction also should be considered. Dissolution of $\mathrm{Cu}$ in iron affected the physical properties as well, and measurements showed a lower electrical conductivity and higher coercive force in this alloy compared to Fe-C.

In case of Fe-Mn-Si-C, the oxygen-sensitive alloying elements ( $\mathrm{Mn}$ and $\mathrm{Si}$ ) were introduced into the Fe- $0.8 \mathrm{C} \mathrm{mix}$ by adding $4 \%$ of a masteralloy powder. The experiments showed that, in this system, oxygen removal from the surface of the plain iron particles occurred through the "Internal Getter" effect at rather low temperature, transferring oxygen to the masteralloy particles. Therefore, the sintering process, including the carbon dissolution and contact formation, did not show significant difference to the Fe-C system. Dimensional change and hardness measurement as well as metallography showed that the alloying process in this system was almost complete at $1100{ }^{\circ} \mathrm{C}$, assisted by Mn homogenization through the gas phase. This alloying process was also discernible from the beginning at moderate temperatures through both electrical conductivity and coercive force measurement. From $1100{ }^{\circ} \mathrm{C}$, the oxygen content was significantly lowered, and the steel showed a pronounced improvement of the impact properties, which placed this variant above all other grades. Achieving a good combination of the impact and hardness properties at this sintering temperature could present this steel as a suitable option for industrial production, which typically uses continuous mesh belt furnaces with the typical operating temperature of $1120^{\circ} \mathrm{C}$.

In the Fe-Cr-Mo-C system, the steel was prepared by mixing Astaloy CrM and 0.8\% graphite. According to the results of the experiments, up to $1000{ }^{\circ} \mathrm{C}$, no indications for sintering contacts and carbon dissolution were observed. The first signs of these phenomena were seen at the sintering temperature of $1000{ }^{\circ} \mathrm{C}$, synchronous with the onset of carbothermal reduction of surface oxides. At this temperature, the process of carbon dissolution was well noticeable by measuring the coercive force as well, However, measurement of the electrical conductivity showed that, unlike for the other steels, carbon dissolution did not result in lower conductivity; apparently, the effect of this process is compensated by the positive effect of surface oxide reduction, and thus enhanced neck formation. The increase of the conductivity between $700-1000{ }^{\circ} \mathrm{C}$ can be attributed to the effect of the tiny metal-metal contacts generated during pressing, which grew even at low temperatures to a degree to improve the conductivity, but not so much that also the mechanical properties were increased. The study showed that the desired mechanical properties (hardness and impact energy) could be achieved only at sintering temperatures of $1200{ }^{\circ} \mathrm{C}$ and above when the oxides were largely removed from the system. In contrast to the other three variants that did not show significant changes of the hardness after sintering above $1100{ }^{\circ} \mathrm{C}$, this steel showed an upward trend in hardness up to $1300^{\circ} \mathrm{C}$. For the impact energy, in contrast, higher sintering temperatures were beneficial in any of the investigated materials.

As a final conclusion, the following statements can be derived: 
- $\quad$ For steel grades that do not contain oxygen-affine alloy elements, the formation and growth of sintering contacts starts already at moderate temperatures. Oxygen removal is typically attained at belt furnace temperatures, as well as satisfactory properties.

- In the case of Fe-C, the dissolution of carbon is the most crucial step that controls the properties.

- $\quad$ For Fe-Cu-C, the formation of transient liquid phase and resulting homogenization of $\mathrm{Cu}$ is a further relevant process that improves hardness and strength while slightly lowering the impact energy.

- Adding oxygen-affine elements through the masteralloy route results in the "internal getter" effect, i.e., oxygen transfer from the iron particle surfaces to the masteralloy particles, but this enhances formation of iron-iron sintering contacts. The masteralloy particles are subsequently reduced carbothermally at higher temperatures.

- $\quad$ For the Cr-Mo pre-alloyed steel, oxygen removal requires fairly high temperatures; this process also triggers off carbon dissolution and formation of solid interparticle contacts. Therefore, this steel variant requires the highest sintering temperatures.

- $\quad$ Fe-C and Fe-Cu-C are well suited for the cost-effective production of standard powder metallurgy precision parts. The Cr-Mo pre-alloyed grade, in contrast, must be sintered under specific conditions, especially at sufficiently high temperatures, which requires special furnaces [47]. However, if properly sintered, this material offers the best property portfolio. The masteralloy approach finally can be regarded as an attractive compromise between production requirements and properties attained.

- Physical properties are useful to describe the homogenization of alloy elements. The electrical conductivity is mainly sensitive to metallic alloy elements while the coercive force mirrors predominantly the dissolution of carbon.

- $\quad$ Further investigations are required to fully establish the property profiles of both prealloyed and masteralloy variants. This holds in particular for the fatigue properties, which are relevant for many applications.

Author Contributions: All authors have read and agreed to the published version of the manuscript.

Funding: This research received no external funding.

Institutional Review Board Statement: Not applicable.

Informed Consent Statement: Not applicable.

Data Availability Statement: $\mathrm{PhD}$ thesis Milad Hojati, TU Wien, in preparation.

Acknowledgments: The authors want to thank Atomising Systems Ltd., Sheffield, UK, for producing and supplying the masteralloy powder used.

Conflicts of Interest: The authors declare no conflict of interest.

\section{References}

1. Kremel, S.; Danninger, H.; Yu, Y. Effect of sintering conditions on particle contacts and mechanical properties of PM steels prepared from 3\% Cr prealloyed powder. Powder Metall. Prog. 2002, 2, 211-221.

2. Zapf, G.; Dalal, K. Introduction of high oxygen affinity elements manganese, chromium and vanadium in the powder metallurgy of P/M parts. In Modern Developments in Powder Metallurgy; Metal Powder Industries Federation: Princeton, NJ, USA, 1977; Volume 10, pp. 129-152.

3. De Oro Calderon, R.; Gierl-Mayer, C.; Danninger, H. Sintering enhancement by the use of masteralloys: Important concepts and new possibilities. In Proceedings of the World Congress on Powder Metallurgy, Beijing, China, 16-20 September 2018; pp. $462-472$.

4. De Oro Calderon, R.; Gierl-Mayer, C.; Danninger, H. Effect of sintering conditions on the properties of lean pm steels produced through the masteralloy route. In Proceedings of the World Congress on Powder Metallurgy, Beijing, China, 16-20 September 2018; pp. 473-480.

5. Kulecki, P.; Lichańska, E.; Sułowski, M. The effect of processing parameters on microstructure and mechanical properties of sintered structural steels based on prealloyed powders. Metall. Mater. 2015, 60, 2543-2549. [CrossRef]

6. Gierl-Mayer, C.; Molnar, C.W.; Danninger, H. Correlations between microstructure, mechanical properties and sintering parameters for PM steels. In Proceedings of the Euro PM Congress and Exhibition, Barcelona, Spain, 9-12 October 2011; pp. 1-7. 
7. Danninger, H.; Gierl, C. Processes in PM steel compacts during the initial stages of sintering. Mater. Chem. Phys. 2001, 67, 49-55. [CrossRef]

8. Höganäs. Handbook for Sintered Components. Iron and Steel Powders for Sintered Components; Höganäs AB: Hoganas, Sweden, 2017

9. De Oro Calderon, R.; Jaliliziyaeian, M.; Dunkley, J.; Gierl-Mayer, C.; Danninger, H. New chances for the masteralloy approach. Powder Metall. Prog. 2018, 18, 121-127. [CrossRef]

10. Fleck, N.; Smith, R. Effect of density on tensile strength, fracture toughness, and fatigue crack propagation behaviour of sintered steel. Powder Metall. 1981, 24, 121-125. [CrossRef]

11. Danninger, H.; Xu, C.; Lindqvist, B. Oxygen removal during sintering of steels prepared from Cr-Mo and Mo prealloyed powders. Mater. Sci. Forum 2007, 534, 577-580. [CrossRef]

12. Cavdar, U. Effect of the copper amount in iron-based powder-metal compacts. Mater. Technol. 2015, 49, 57-62.

13. Wong-Ángel, W.D.; Téllez-Jurado, L.; Chávez-Alcalá, J.F.; Chavira-Martínez, E.; Verduzco-Cedeño, V.F. Effect of copper on the mechanical properties of alloys formed by powder metallurgy. Mater. Des. 2014, 58, 12-18. [CrossRef]

14. Pang Jianming, F.J.; Congchao, P.; Yaoxin, S. Effect of copper powder on the properties of iron-based powder metallurgy sintered products. In Proceedings of the World Congress on Powder Metallurgy, Beijing, China, 16-20 September 2018; pp. 98-106.

15. Hu, H.; Xu, G.; Zhou, M.; Yuan, Q. Effect of Mo content on microstructure and property of low-carbon bainitic steels. Metals 2016, 6, 173. [CrossRef]

16. Sakuma, Y.; Matlock, D.K.; Krauss, G. Effect of molybdenum on microstructure and mechanical properties of intercritically annealed and isothermally transformed low carbon steel. Mater. Sci. Technol. 1993, 9, 718-724. [CrossRef]

17. Danninger, H.; De Oro Calderon, R.; Gierl-Mayer, C. Chemical reactions during sintering of PM steel compacts as a function of the alloying route. Powder Metall. 2018, 2018. 61, 241-250. [CrossRef]

18. Danninger, H.; De Oro Calderon, R.; Gierl-Mayer, C. Oxygen transfer reactions during sintering of ferrous powder compacts. Adv. Eng. Forum 2018, 27, 3-13. [CrossRef]

19. Danninger, H.; De Oro Calderon, R.; Gierl-Mayer, C. Surface chemistry of metal powders and changes during the sintering process. In Proceedings of the World Congress on Powder Metallurgy, Beijing, China, 16-20 September 2018; pp. 92-97.

20. Gierl-Mayer, C.; Danninger, H. Dilatometry coupled with mass spectrometry as instrument for process control in sintering of powder metallurgy steels. Mater. Sci. Forum 2016, 835, 106-115. [CrossRef]

21. Karamchedu, S.; Hryha, E.; Nyborg, L. Changes in the surface chemistry of chromium-alloyed powder metallurgical steel during delubrication and their impact on sintering. J. Mater. Process. Technol. 2015, 223, 171-185. [CrossRef]

22. Danninger, H.; De Oro Calderon, R.; Gierl-Mayer, C. Powder metallurgy and sintered materials. In Ullmann's Encyclopedia of Industrial Chemistry; Wiley-VCH Verlag: Weinheim, Germany, 2017; pp. 1-57.

23. Dudrova, E.; Kabátova, M. A review of failure of sintered steels: Fractography of static and dynamic crack nucleation, coalescence, growth and propagation. Powder Metall. 2016, 59, 148-167. [CrossRef]

24. Danninger, H. Pore formation during sintering of Fe-Cu and its effects on mechanical properties. Powder Metall. Int. 1987, 19, 19-23.

25. German, R.M.; Suri, P.; Park, S.J. Review: Liquid phase sintering. J. Mater. Sci. 2009, 44, 1-39. [CrossRef]

26. Danninger, H.; Gierl-Mayer, C.; Strobl, S. Evolution of microstructure in ferrous and non-ferrous materials. In Advances in Powder Metallurgy; Chang, I., Zhao, Y., Eds.; Woodhead Publishing: Sawston, UK, 2013; pp. 308-357.

27. Lawcock, R.L.; Davies, T.J. Effect of carbon on dimensional and microstructural characteristics of Fe-Cu compacts during sintering. Powder Metall. 1990, 33, 147-149. [CrossRef]

28. Fredriksson, H.; Hansson, K.; Olsson, A. On the mechanism of liquid copper penetration into iron grain boundaries. Scand. J. Metall. 2001, 30, 41-50. [CrossRef]

29. Jamil, S.J.; Chadwick, G.A. Investigation and analysis of liquid phase sintering of Fe-Cu and Fe-Cu-C compacts. Powder Metall. 1985, 28, 65-71. [CrossRef]

30. Kieback, B.; Schatt, W. Anwendung eines kurzzeitigen Flüssigphasensinterns für die Herstellung von Fe-Ti-Sinterlegierungen. Planseeberichte für Pulvermetallurgie 1980, 28, 204-215.

31. Šalak, A.; Selecká, M. Alloying and sintering of manganese steels by manganese vapour. In Manganese in Powder Metallurgy Steels; Cambridge International Science Publishing: Cambridge, UK, 2012; pp. 39-72.

32. Baselli, S.; Molinari, A. Sintering shrinkage of cold compacted iron-Effect of thermodynamic driving force, structural and geometrical activity. Powder Metall. 2021, 64, 126-133. [CrossRef]

33. Dautzenberg, N.; Dorweiler, H.J. Dimensional behaviour of copper-Carbon sintered steels. Powder Metall. Int. 1985, 17, $279-282$.

34. Danninger, H.; Frauendienst, G.; Streb, K.-D.; Ratzi, R. Dissolution of different graphite grades during sintering of PM steels. Mater. Chem. Phy. 2001, 67, 72-77. [CrossRef]

35. Zhang, Z.; Sandström, R.; Wang, L. Modelling of swelling of Fe-Cu compacts sintered at temperatures above the copper melting point. J. Mater. Process. Technol. 2004, 152, 131-135. [CrossRef]

36. Magee, B.E.; Lund, J. Mechanisms of liquid-phase sintering in iron-copper powder compacts. Zeitschrift für Metallkunde 1976, 67, 596-602. [CrossRef]

37. Wanibe, Y.; Yokoyama, H.; Itoh, T. Expansion during liquid phase sintering of iron-copper compacts. Powder Metall. 1990, 33, 65-69. [CrossRef] 
38. Berner, D.; Exner, H.E.; Petzow, G. Swelling of iron-copper mixtures during sintering and infiltration. Mod. Dev. Powder Metall. 1974, 6, 237-250.

39. Šalak, A.; Selecka, M.; Bures, R. Manganese in ferrous powder metallurgy. Powder Metall. Prog. 2001, 1, 41-58.

40. Momeni, M. Temperature and Interstitial Effect on Physical and Chemical Processes During Sintering of Ferrous Powder Compacts. Ph.D. Thesis, Technische Universität Wien, Vienna, Austria, 2010.

41. Momeni, M.; Gierl, C.; Danninger, H. Electrical conductivity and microstructural changes of sintered plain carbon steels prepared from different base powders. In Proceedings of the Euro PM Congress and Exhibition, Copenhagen, Denmark, 12-14 October 2009; pp. 1-6.

42. Simchi, A.; Danninger, H.; Gierl, C. Electrical conductivity and microstructure of sintered ferrous materials: Iron-graphite compacts. Powder Metall. 2001, 44, 148-156. [CrossRef]

43. Simchi, A.; Danninger, H. Electrical conductivity and microstructure of sintered ferrous materials: Sintered iron. Powder Metall. 2000, 43, 209-218. [CrossRef]

44. Jangg, G.; Drozda, M.; Eder, G.; Danninger, H. Magnetic properties of sintered iron-Influence of the microstructure of sintered iron materials on the coercive force. Powder Metall. Int. 1984, 16, 60-64.

45. Jangg, G.; Drozda, M.; Danninger, H.; Nad, R.E. Magnetic properties of sintered iron-The influence of porosity on the magnetic properties of sintered iron. Powder Metall. Int. 1983, 15, 173-177.

46. Jiles, D.C. Magnetic properties and microstructure of AISI 1000 series carbon steels. J. Phys. D Appl. Phys. 1988, 21, 1186-1195. [CrossRef]

47. Arnhold, V.; Kruzhanov, V. Hochtemperatursintern von niedriglegierten PM-Stählen (High temperature sintering of low alloy PM steels). In Pulvermetallurgie in Wissenschaft und Praxis, Proceedings of Hagen PM Symposium, Hagen, Germany, 25-26 November 2021; Fachverband Pulvermetallurgie: Hagen, Germany, 2021; Volume 36, pp. 233-252. (In German) 